Am. J. Trop. Med. Hyg., 79(5), 2008, pp. 742-749

Copyright (C) 2008 by The American Society of Tropical Medicine and Hygiene

\title{
Trypanosoma cruzi Transmission Cycle Among Wild and Domestic Mammals in Three Areas of Orally Transmitted Chagas Disease Outbreaks
}

\author{
André Luiz R. Roque, Samanta C. C. Xavier, Marconny G. da Rocha, Ana Cláudia M. Duarte, Paulo S. D’Andrea, \\ and Ana M. Jansen* \\ Laboratory of Tripanosomatid Biology, Oswaldo Cruz Institute, FIOCRUZ, Rio de Janeiro, Brazil; Laboratory of Leishmaniasis \\ Research, Oswaldo Cruz Institute, FIOCRUZ, Rio de Janeiro, Brazil; Laboratory of Biology and Parasitology of Wild Reservoir \\ Mammals, Oswaldo Cruz Institute, FIOCRUZ, Rio de Janeiro, Brazil
}

\begin{abstract}
We report Trypanosoma cruzi infection in wild and domestic mammals from three orally acquired Chagas disease outbreak areas in Brazil. Cachoeiro do Arari (Pará) displayed a panzootic scenery (positive mammals in all ecologic strata), and human cases were probably the consequence of their exposure within the sylvatic $T$. cruzi transmission cycle. In Navegantes (Santa Catarina), Didelphis spp. was the main reservoir host, given that $93 \%$ were infected. In Redenção (Ceará), Monodelphis domestica and Thrichomys laurentius were also important for parasite maintenance. TCI was present in the three studied areas. Additionally, Z3 was detected in an armadillo from Pará and TCII in a triatomine from Navegantes. Domestic animals showed a high seroprevalence and should be considered sentinels in surveillance programs. The importance of a reduction in wild mammalian fauna diversity and selection of suitable $T$. cruzi reservoir hosts are discussed as risk factors for the re-emergence of Chagas disease.
\end{abstract}

\section{INTRODUCTION}

Since June 2006, Brazil has been considered free from Chagas disease transmission caused by Triatoma infestans. This was the conclusion of the 15 th annual meeting of the Intergovernmental Commission of the Southern Cone Initiative against Chagas disease. ${ }^{1}$ Nevertheless, this statement is far from descriptive of the possibility of Trypanosoma cruzi transmission to humans. That is because intradomiciliary transmission caused by $T$. infestans, an introduced exogenous species, ${ }^{2,3}$ represents an important, but not the only, mechanism of human infection. The other forms of transmission include organ transplantation, blood transfusion, congenital routes, and oral transmission because of the ingestion of contaminated food. ${ }^{4}$ The latter is currently acquiring an important role in Brazil. .,6 $^{5}$

The causative agent of Chagas disease, T. cruzi, is a digenetic kinetoplastid, primarily an enzootic parasite that displays great genetic variability, mainly attributed to a long clonal evolution process in its almost 100 wild mammal host species. ${ }^{7}$ In South America, T. cruzi has circulated in the autochthonous mammalian fauna since its speciation. ${ }^{8,9}$ Since that time, it continuously spread into the fauna that arrived from 40 to 5 million years (myr) ago in different migration waves. ${ }^{10,11}$ The first evidence of human infection by $T$. cruzi came from Andean mummified human tissue, $\sim 9,000$ years ago. ${ }^{12}$ Others also found T. cruzi DNA from mummified human tissue from 7,000 years ago in Brazil. ${ }^{13}$ In fact, humans probably entered in the $T$. cruzi transmission cycle immediately on their arrival in America.

Two main genotypes of the parasite (TCI and TCII) can be distinguished, whereas the relatedness of a third one $(\mathrm{Z} 3)$ is still under debate. ${ }^{14,15}$ Thus far, the three genotypes have been described infecting wild mammals throughout the country, except in the Amazonian region where TCII has not been described as yet. In the Pantanal region, TCI and TCII may

\footnotetext{
* Address correspondence to Ana M. Jansen, Laboratory of Tripanosomatid Biology, Oswaldo Cruz Institute, FIOCRUZ, Av. Brasil 4365, Pav. Carlos Chagas, 3 andar, CEP 21040-900, Rio de Janeiro/ RJ, Brazil. E-mail: jansen@ioc.fiocruz.br
}

be found infecting mammals in a similar ratio, whereas Z3infected mammals are less numerous. Moreover, in this biome that displays an impressive diversity of mammal hosts, these genotypes may be observed in single or mixed infections in all possible combinations. ${ }^{16}$

Concerning human cases in Brazil, except for the Amazonian region, they have always been associated with TCII, but even this assumption has come into question. Parasites obtained from infected patients in Icoaraci (Pará state [PA]) and Catolé do Rocha (Paraíba state $[\mathrm{PB}]$ ) were characterized as TCI. ${ }^{17}$ In contrast, all the isolates derived from humans infected during the outbreak in Navegantes (Santa Catarina state [SC]) in 2005 belonged to the TCII genotype. ${ }^{18}$

Although ignored by the Southern Cone Initiative, orally acquired infection is not a recent epidemiologic picture in Chagas disease. The first description of this kind of transmission was attributed to, among others sources, food contaminated by opossum urine. ${ }^{19}$ This was almost 20 years before the description of the extracellular cycle of $T$. cruzi in the opossum's anal gland. ${ }^{20}$ Almost 30 years passed before new cases of human disease contracted by digestive infection were reported, this time associated with sugar cane in the northeastern parts of Brazil in Paraíba state. ${ }^{21}$ In recent years, these oral outbreaks have become more frequent, and several human cases have been reported. These cases occurred in different localities of the country that were formerly not considered endemic for Chagas disease and were always associated with severe acute forms of the disease and human deaths. These epidemic outbreaks were seen, among others, in 1) Navegantes (SC, south Brazil), 2005, attributed to sugar cane juice ingestion; 2) Santana (Amapá state [AP], Amazonian basin), 2005, attributed to the ingestion of contaminated Açaí juice, a regional fruit; 3) Redenção (Ceará state [CE], northeastern Brazil), 2006, attributed to ingestion of contaminated soup; 4) Macaúbas (Bahia state [BA], northeastern Brazil), 2006; and 5) Santarém, Belém, and Cachoeiro do Arari (PA, north Brazil), 2006, attributed to the ingestion of the regional fruits, Açaí and Bacaba. 5,18,22,23

To understand the environmental changes that could be implicated in these outbreaks, we studied the domestic and wild mammalian fauna in the influence area of occurrence of 
three Chagas disease outbreaks: Navegantes (SC), Redenção (CE), and Cachoeiro do Arari (PA). Beyond the classic picture of the entrance of humans into the active transmission cycle of the parasite, the reduction of wild mammalian fauna diversity and the selection of suitable reservoirs were examined as risk factors for the outbreaks. The zoonotic sceneries of each place are discussed.

\section{MATERIALS AND METHODS}

Study areas. Expeditions were conducted shortly after the Chagas disease outbreaks in April 2005 (Navegantes/SC) and May and November 2006 (Redenção/CE and Cachoeiro do Arari/PA, respectively; Figure 1). In all of these places, wild and domestic animals in the areas where the human cases occurred were studied.

Navegantes is located around latitude $26^{\circ} 52^{\prime} 48^{\prime \prime}$ and longitude $48^{\circ} 39^{\prime} 00^{\prime \prime}$, at $2 \mathrm{~m}$ above sea level on the cost of the Santa Catarina state. The population is estimated to be 45,000 inhabitants and has a tropical climate, with temperatures ranging between $10^{\circ} \mathrm{C}$ and $35^{\circ} \mathrm{C}$. The predominant biome is the
Atlantic rainforest. In all collection areas, herbaceous and forest fragments were surrounded by extensive areas of agriculture. Animals and bugs from the forest fragment behind the shoal where human infections took place were examined, as well as animals from a small town and forest fragments near that shoal.

Redenção is located in the Baturité mountain range region, around latitude $4^{\circ} 13^{\prime} 32^{\prime \prime}$ and longitude $38^{\circ} 43^{\prime} 50^{\prime \prime}$, at $89 \mathrm{~m}$ above sea level. The population is estimated to be $\sim 26,000$; the climate is semi-arid with scarce rainfall between January and April and temperatures ranging between $24^{\circ} \mathrm{C}$ and $35^{\circ} \mathrm{C}$. The collection area, originally part of a tropical semi-humid forest, is currently characterized by secondary vegetation consisting of low trees $(\leq 6 \mathrm{~m})$, rocky formations, and remnant patches of semi-humid forest near deforested areas occupied by monoculture plantations or unplanned household occupation (slum).

Cachoeiro do Arari is one of the cities included in Marajó Island, located around latitude $01^{\circ} 00^{\prime} 41^{\prime \prime}$ and longitude $48^{\circ} 57^{\prime} 48^{\prime \prime}$, at $20 \mathrm{~m}$ above sea level. Only 17,000 inhabitants are living in an area of $3,117 \mathrm{~km}^{2}$. The climate is characterized as

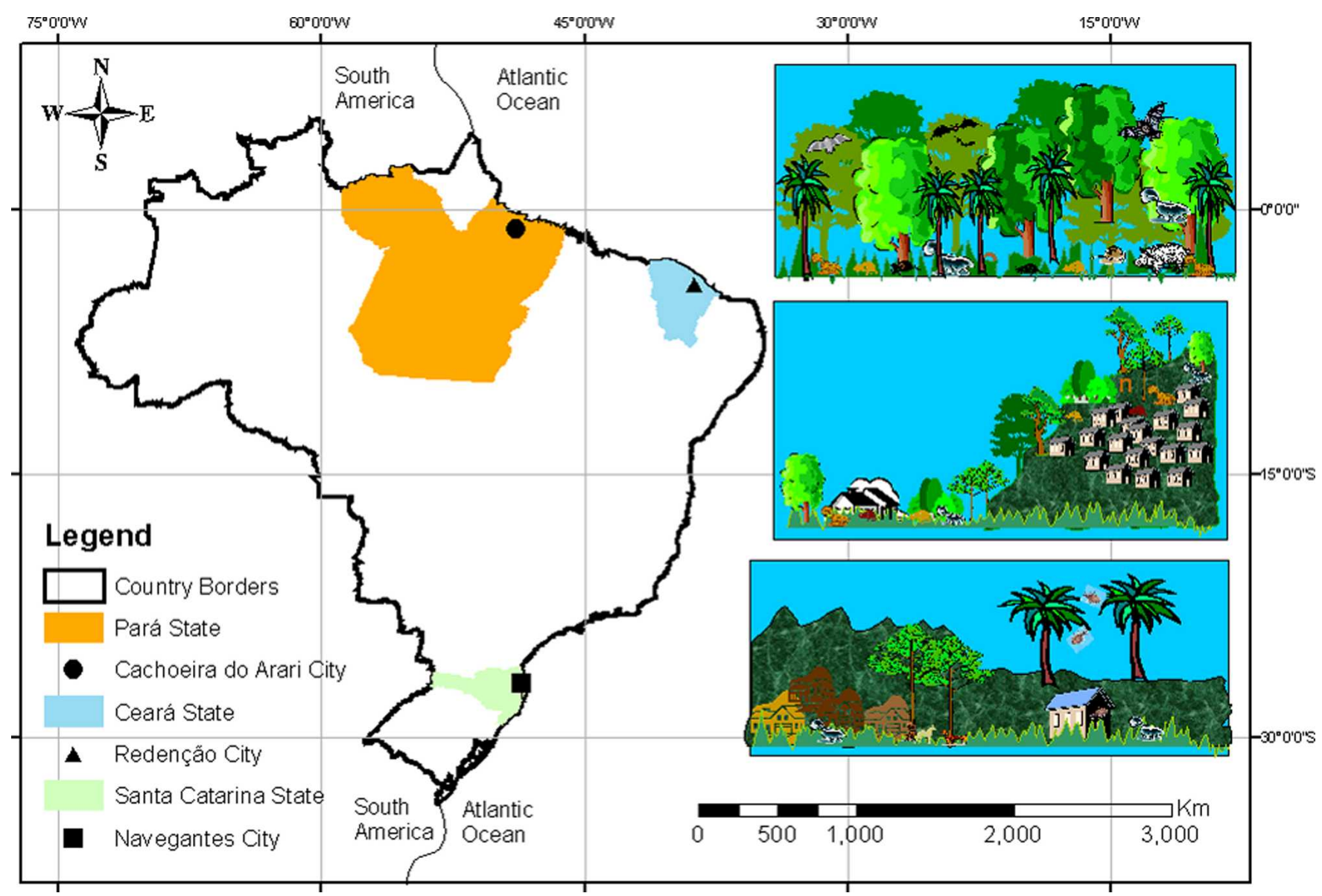

Figure 1. Map of the distribution of recent Chagas disease outbreaks in Brazil (Navegantes city-April 2005; Redenção and Cachoeiro do Arari cities-May and November 2006, respectively) and their representative natural environments involved in the $T$. cruzi transmission cycle. $\mathbf{\square}=$ T. cruzi-infected Didelphis spp. and Triatoma tibiamaculata were found in palm trees immediately behind the shoal where human infections took place and in forest fragments that surround the shoal. Infected opossums and dogs were also found in a small town and in forest fragments near that shoal. $\boldsymbol{\Delta}=$ All collected small mammal species $(N=4)$ were found to be infected by $T$. cruzi in the forest fragments behind the slum where human infections took place. Three of these four species were also captured and found to be infected by $T$. cruzi in rural areas of this municipality. $\boldsymbol{0}$ = Panzootic scenery where $T$. cruzi-infected mammals were captured in all of the forest strata (terrestrial, arboreal, and flying animals), in an Amazonian area characterized by an extensive Açaí fruit monoculture with a few remaining patches of the original vegetation. This figure appears in color online at www.ajtmh.org. 
tropical humid, displaying regular rainfalls and winds, and temperatures range between $27^{\circ} \mathrm{C}$ and $36^{\circ} \mathrm{C}$. The area is known as varzean, a freshwater swamp forest. In most of the collection areas, the original native vegetation (Amazonian forest) is being replaced by an extensive Açaí fruit monoculture with a few remaining patches of the original vegetation at the river banks.

Wild mammal studies. For each place, linear transects were generated, and the capture points were established with Tomahawk (Tomahawk Live Traps, Tomahawk, WI) and Sherman (H. B. Sherman Traps, Tallahassee, FL) baited with a mixture of peanut butter, banana, oat, and bacon and set 20 $\mathrm{m}$ apart along linear transactions in all kind of vegetation formations and habitats. The total effort was 820 (SC), 960 (CE), and 1,100 traps/night (PA), and the capture success was $2.6 \%$ (SC), $2.9 \%(\mathrm{CE})$, and $2.4 \%$ (PA). The trapped animals were taken to the field laboratory, $\leq 2 \mathrm{~km}$ from the capture point, where the remaining procedures were undertaken. All manipulators were adequately dressed with protective equipment, following protocols approved by the FIOCRUZ Committees of Biosafety and of Bioethics (license 0179-03). The wild animal captures were licensed by the Brazilian Institute of Environment and Renewable Natural Resources (IBAMA) licenses 068-2005 and 225-2006 (IBAMA/ CGFAU/LIC). For each captured species, morphological identification, reproductive condition, and age estimation (body weight for rodents and degree of tooth eruption for marsupials) were recorded. The identification of rodents and bats was confirmed by karyriologic analyses as described elsewhere. $^{24}$

Sample collection. Blood was collected from domestic animals (dogs and pigs) by puncture of the cephalic vein in heparinized vacutainers, with the informed consent of their owners. These blood samples were carried to the field laboratory for further procedures. Wild animals were anesthetized (ketamine, $100 \mathrm{mg} / \mathrm{kg}$ ) and had their blood collected by cardiac puncture in non-heparinized tubes. Fresh blood samples were gathered and processed as follows: $0.2-0.4 \mathrm{~mL}$ of blood was cultured in two tubes containing Novy-Mc Neal-Nicole medium (NNN) with a liver infusion tryptose medium (LIT) overlay. The remaining blood was centrifuged, and the serum or plasma obtained was stored at $-20^{\circ} \mathrm{C}$. Although triatomine collection was not the aim of our work, bugs from Navegantes/SC, when observed in domestic or peridomestic areas, were collected. If tripomastigote forms were seen, the animal's feces were cultured in tubes containing NNN with a LIT overlay. A total of nine insects were examined.

Parasitologic and serologic diagnostic procedures. The fresh blood samples from all animals and the anal glands of Didelphis specimens were microscopically examined in the field laboratory for the presence of $T$. cruzi. In our laboratory, the hemocultures were examined every other week for 5 months. Positive hemocultures were amplified for cryopreservation and molecular characterization.

Serologic diagnoses were obtained using the indirect immunofluorescence antibody test (IFAT), performed with the adapted IFI-Chagas Bio-Manguinhos Kit (Fiocruz, Rio de Janeiro, Brazil). ${ }^{25}$ Muridae rodents' sera were tested with fluorescein isothiocyanate (FITC) anti-rat, whereas domestic animals were tested with their respective anti-species IgG (Sigma, St. Louis, MO) conjugate. Echimyidae rodent and marsupial serologic diagnoses were performed with specific intermediary antibodies anti-opossum and anti-Thrichomys sera previously raised in rabbits, and the reaction was visualized using the FITC-labeled anti-rabbit serum (Sigma). The cut-off value for wild animals was 1:40 for marsupials and 1:10 for the others, as adopted in other studies. These cut-off values were based on the lowest serum dilution of an animal with positive hemoculture in previous studies of our group. ${ }^{26,27}$ For domestic animals, the cut-off value adopted was 1:40, as suggested by the Ministry of Health. ${ }^{28}$ The dogs were also screened for Leishmania infection using an IFI-Leishmania Bio-Manguinhos Kit (Fiocruz). Dogs with higher serologic titers for Leishmania than T. cruzi were not considered infected by $T$. cruzi. When the amount of blood was not sufficient, priority was given to hemoculture. Animals were considered infected by $T$. cruzi when serologic analysis or hemoculture was positive. Hemoculture prevalence was calculated considering the seropositive animals.

Molecular characterization of the parasites. The amplified positive hemocultures derived from mammals $(N=17)$ and triatomines $(N=3)$ were incubated at $56^{\circ} \mathrm{C}$ for 2 hours with $100 \mu \mathrm{g} / \mathrm{mL}$ proteinase $\mathrm{K}$ and $0.5 \%$ sodium dodecyl sulfate (SDS). Genomic DNA was extracted from parasite lysates using phenol-chloroform (1:1) and precipitated with sodium acetate and ethanol. ${ }^{29}$ A miniexon Multiplex PCR assay was performed using the following primers: TCI, 5'-ACACTTTCTGTGGCGCTGATCG-3'; TCII, 5' -TTGCTCGCACACTCGGCTGATCG-3'; Z3, 5'-CCGCGWACAACCCCTMATAAAAATG-3'; Trypanosoma rangeli, 5' CCTATTGTGATCCCCATCTTCG-3'; and the conserved region of miniexon gene 5'-TACCAATATAGTACAGAAACTG- $3^{\prime} .^{30}$ The amplified polymerase chain reaction (PCR) products were analyzed in ethidium bromide-stained agarose gel electrophoresis (2\%) and visualized under UV light.

\section{RESULTS}

Each one of the outbreak's locations showed a unique epidemiologic scenery concerning the fauna composition involved in parasite maintenance in the wild and the degree of human disturbance (Figure 1). In Navegantes and Redenção, the small mammalian fauna was predominantly composed of synantropic animals. In Navegantes, the suitable reservoir species were Didelphis aurita and D. albiventris, which displayed high parasitemia, as expressed by the high prevalence of positive hemocultures. In Redenção, the small mammalian fauna diversity was restricted to three species: D. albiventris, Monodelphis domestica, and Thrichomys laurentius. The more preserved area, Cachoeiro do Arari, displayed the higher diversity of small mammalian fauna ( $N=8$ species) and a panzootic scenery, with positive hemocultures in mammals captured in all of the forest strata (terrestrial, arboreal, and flying mammals).

Trypanosoma cruzi infection in wild mammals and triatomines. Trypanosoma cruzi infection in mammals was mainly sub-patent because only two marsupial species (one D. albiventris from Navegantes and one $M$. domestica from $\mathrm{Re}$ denção) displayed tripomastigote forms in fresh blood preparations and no parasites were observed in the anal glands. Species of the synantropic marsupial genus Didelphis comprised the unique small mammalian host present in all areas studied, displaying a high relative abundance. The overall 
positive seroprevalence of this genus reached $88.5 \%$, and positive hemocultures were detected in $52.2 \%$ of the infected animals (Tables 1-3).

In Navegantes (SC), only the synantropic genus Didelphis represented the main reservoir system due to their high transmission potential, as shown by the high prevalence of positive hemocultures and high relative abundance of these species. In addition, these mammals were the only two species infected by $T$. cruzi, and $67 \%$ of them were captured in peridomestic areas (Table 1). In Navegantes, the two main genotypes of the parasite (TCI and TCII) were isolated from two infected bugs collected in the palm trees, immediately beneath the area where infected opossums were also collected and near the shoal where humans became infected. Another bug was collected inside a residence, and its isolate was characterized as TCII.

In Redenção (CE), where only synantropic species were collected, young animals prevailed throughout (64.3\%). All collected rodent species were involved in the maintenance of the parasite transmission, because all of them were seropositive (Table 2). Marsupials were involved not only in the maintenance but also in the amplification of the $T$. cruzi transmission cycle, because $56 \%$ of positive hemocultures were obtained from $60 \%$ of the infected animals, with three coming from seronegative animals (Table 2). One M. domestica showed trypanosomatids in a fresh blood smear. An active peridomiciliary transmission cycle could be observed, given that representatives of the collected species $(28.6 \%)$ were found in peridomestic areas, showing $75 \%$ serum positivity and $33.3 \%$ positive hemocultures.

In comparison to the other outbreak areas, Cachoeiro do Arari (PA) displayed the highest mammalian fauna diversity (Table 3). All collected species except two showed high suitability as reservoirs (high transmissibility) because positive hemocultures were obtained from all of them. The most abundant species were Proechimys goeldii, D. marsupialis, and Hylaeamys spp. (=Oryzomys spp.). Of these species, D. marsupialis displayed the higher serum and hemoculture prevalence (Table 3). It is worth mentioning that hemoculturepositive-tested animals were captured in all of the forest strata, pointing to a complex and well-established transmission cycle in this study area.

Altogether, 17 isolates were obtained from mammals. All of them were characterized as TCI, except one from the Dasypus novemcintus captured in Cachoeiro do Arari, which was characterized as $\mathrm{Z3}$.

Trypanosoma cruzi infection in the domestic mammals. In all studied areas, domestic animals were exposed to infection, as shown by the presence of anti-T. cruzi antibodies, but they seem to play a minor role in the $T$. cruzi transmission net. Actually, despite the high seroprevalence observed in dogs and pigs (Table 4), all of them displayed low parasitemias given that no positive hemoculture was achieved $(N=37)$, and fresh blood sample examinations $(N=84)$ were negative.

The pigs from Cachoeiro do Arari, which were predominantly $(63.6 \%)$ settled in sylvatic areas (disturbed ones) near açaí plantations, were the domestic animals with highest seroprevalence $(72.7 \%)$.

\section{DISCUSSION}

The oral route is probably the most ancient dispersion strategy of $T$. cruzi among mammals (including humans). The efficiency of this route is attested by several reports on experimental infection of mice and opossums by ingestion of $T$. cruzi-infected triatomines and/or mice. ${ }^{31,32}$ In addition, it was recently observed that the gastric juice improves the infective potential of the parasite. ${ }^{33,34}$ Indeed, infection by the oral route may better explain infection of predators (top of food webs) rather than skin contamination with infected feces of triatomines in the often dense animal fur. This is also probably the case with primitive hunting communities that were recognized consumers of raw meat ${ }^{35}$ and probably were not very concerned about washing hands or foodstuffs.

All of the cited outbreaks resulted from the ingestion of comestibles contaminated with infected non-domiciliated triatomines that occasionally entered human dwellings because of attraction to light and food sources. ${ }^{5,23}$ In fact, the increase of flying activity of the triatomine winged stages in warmer seasons has already been described. ${ }^{6}$ Fragmentation and the resultant habitat loss are the primary causes of loss of biodiversity because of 1) reduction or elimination of some habitat specialist species, and therefore, of diversity; and 2) positive selection of generalist species that can adapt and survive in the consequent degradated habitats. ${ }^{36,37}$ The consequence of this process is the increased opportunity for contact among humans, domestic animals, and wildlife. ${ }^{38}$

Empirical evidence shows that habitat fragmentation can increase or decrease disease prevalence within a host species, depending on the specific biology of the host-parasite relationship. ${ }^{39}$ Increased species diversity could reduce human disease risk by impeding dominance of particular species that act as suitable reservoirs of a given parasite. Therefore, depending on the ability of the selected species to maintain and/or amplify a given parasite, transmission of this parasite

TABLE 1

Capture and prevalence of infection by T. cruzi in the small mammalian fauna in Navegantes (Santa Catarina state, Brazil), just after the occurrence of a Chagas disease outbreak in April 2005

\begin{tabular}{|c|c|c|c|c|c|}
\hline \multicolumn{3}{|c|}{ Capture of the small mammalian fauna } & \multicolumn{3}{|c|}{ Prevalence of infection } \\
\hline Order & Species & Capture prevalence (number of animals) & Serology (positive animals) & Hemoculture (parasite recovery) & Parasite characterization \\
\hline \multirow[t]{4}{*}{ Rodentia } & Akodon montensis & $13.6 \%(3)$ & $0 \%$ & $0 \%$ & - \\
\hline & Euryoryzomys russatus & $13.6 \%(3)$ & $0 \%$ & $0 \%$ & - \\
\hline & Mus musculus & $4.5 \%(1)$ & $0 \%$ & ND & - \\
\hline & Sphiggurus spp. & $4.5 \%(1)$ & ND & $0 \%$ & - \\
\hline \multirow[t]{3}{*}{ Marsupialia } & Didelphis albiventris & $40.9 \%(9)$ & $88.9 \%(8)$ & $25.0 \%(2)$ & ND \\
\hline & Didelphis aurita & $22.7 \%(5)$ & $100 \%(5)$ & $60.0 \%(3)$ & TCI (2) \\
\hline & Total & $100 \%(22)$ & $59.1 \%(13)$ & $38.5 \%(5)$ & TCI (2) \\
\hline
\end{tabular}


TABLE 2

Capture and prevalence of infection by $T$. cruzi in the small mammalian fauna in Redenção (Ceará state, Brazil), just after the occurrence of a Chagas disease outbreak in May 2006

\begin{tabular}{|c|c|c|c|c|c|}
\hline \multicolumn{3}{|c|}{ Capture of the small mammalian fauna } & \multicolumn{3}{|c|}{ Prevalence of infection } \\
\hline Order & Species & Capture prevalence (number of animals) & Serology (positive animals) & Hemoculture (parasite recovery) & Parasite characterization \\
\hline \multirow[t]{2}{*}{ Rodentia } & Rattus rattus & $7.1 \%(2)$ & $100 \%(2)$ & $0 \%$ & - \\
\hline & Thrichomys laurentius & $39.3 \%(11)$ & $100 \%(11)$ & $0 \%$ & - \\
\hline \multirow[t]{3}{*}{ Marsupialia } & Didelphis albiventris & $17.9 \%(5)$ & $60.0 \%(3)$ & $33.3 \%(1)$ & TCI (1) \\
\hline & Monodelphis domestica & $35.7 \%(10)$ & $60.0 \%\left(3+3^{*}\right)$ & $66.7 \%(1+3 *)$ & TCI (3) \\
\hline & Total & $100 \%(28)$ & $78.6 \%(22)$ & $22.7 \%(5)$ & TCI (4) \\
\hline
\end{tabular}

* Seronegative animal where parasites could be recovered.

may be enhanced. The herein described epidemiologic profile seems to be associated with at least one of the following factors: 1) loss of food sources for triatomines caused by deforestation and human colonization ${ }^{40} ; 2$ ) reduction of mammalian diversity and selection of suitable reservoirs ${ }^{41-43}$; and 3) high wild mammalian infection rates. ${ }^{44}$

The marsupials D. albiventris, D. aurita, D. marsupialis, and $M$. domestica and the rodent species $P$. goeldii and T. laurentius prevailed overall (Tables 1-3). The epidemiologic importance of these mammals is increased because all of them (except for $P$. goeldii) are recognized synanthropic animals and can approach human dwellings, acting as a link between the transmission in sylvatic and peridomestic areas. ${ }^{26,45,46}$

Navegantes and Redenção are unpreserved areas where loss of biodiversity and habitat destruction are shown by both aspects: the low diversity of small mammal species collected and the exclusive presence of synantropic animals. In both outbreak areas, the reduced small mammalian diversity and the selection of suitable reservoir hosts of $T$. cruzi were the common traits observed and should be considered as one of the possible factors that enhanced chances of human infection. A similar scenery was already described for other parasitic diseases, such as Lyme disease, American Cutaneous Leishmaniasis, Hantavirus, and West Nile virus. ${ }^{44,46-49}$ Moreover, and considering $T$. cruzi, it was reported that habitat fragmentation and loss of small mammal diversity may favor transmission among wild small mammals in an Atlantic Rain Forest landscape. ${ }^{27}$ Small mammalian diversity reduction associated with an increase of suitable $T$. cruzi hosts enhances the chance of the vector (triatomines) feeding on an infected animal. This causes an increase in the parasite population, and, as a result, the transmission cycle is amplified. It is hard to imagine that the triatomines only recently started to fall down in soups or juices. More likely, they always were accidentally ingested by humans, especially during the summer, when high temperatures favor bug activity. The absence of infection is probably explained by the fact that fewer insects and uninfected insects were involved in these cases.

Species of the genus Didelphis, considered the classic and most important reservoirs of $T$. cruzi, are basically synanthropic and are favored by human disturbance. For these reasons, they are highly prevalent in disturbed areas, and their higher abundance is strongly indicative of a loss of small mammalian diversity. ${ }^{45,50}$ Indeed, opossums were the most abundant captured animals and displayed the highest serum and hemoculture prevalence in all studied areas. The importance of these animals is increased by the fact that they may eventually act as vectors of the parasite, allowing parasite transmission through food contaminated with their scent gland contents. ${ }^{19,20,51}$

In Navegantes, the two species of Didelphis were highly abundant (65\% of the collected mammals), and $93 \%$ of these were infected. The five isolates obtained were characterized as TCI, whereas both genotypes of the parasite could be isolated from local triatomines. These results are in accordance with another study of that outbreak, which also characterized nine isolates from humans, all of them belonging to the TCII genotype. ${ }^{18}$ Considering the genotype involved in human infection and the fact that both $T$. cruzi genotypes could be detected in triatomines, the absence of TCII found infecting mammals in our study may be explained by 1) selection of the TCI genotype by any component involved in that parasitic net or 2) the relative abundance of the mammals infected with TCII was too low to allow their capture.

In Redenção, the local transmission net of $T$. cruzi was shown to be dependent on three small mammal species. Here,

TABLE 3

Capture and prevalence of infection by T. cruzi in the small mammalian fauna in Cachoeiro do Arari (Pará state, Brazil), just after the occurrence of a Chagas disease outbreak in November 2006

\begin{tabular}{|c|c|c|c|c|c|}
\hline \multicolumn{3}{|c|}{ Capture of the small mammalian fauna } & \multicolumn{3}{|c|}{ Prevalence of infection } \\
\hline Order & Species & Capture prevalence (number of animals) & Serology (positive animals) & Hemoculture (parasite recovery) & Parasite characterization \\
\hline \multirow{2}{*}{ Rodentia } & Hylaeamys spp. & $22.6 \%(7)$ & $28.6 \%(2)$ & $50.0 \%(1)$ & TCI (1) \\
\hline & Proechimys goeldii & $35.6 \%(11)$ & $18.2 \%(1+1 *)$ & $50.0 \%(1)$ & TCI (1) \\
\hline \multirow[t]{2}{*}{ Marsupialia } & Didelphis marsupialis & $22.6 \%(7)$ & $100 \%(7)$ & $85.7 \%(6)$ & TCI (6) \\
\hline & Marmosops parvidens & $3.2 \%(1)$ & $100 \%(1)$ & $0 \%$ & - \\
\hline Edentata & Dasypus novemcinctus & $3.2 \%(1)$ & ND & $100 \%(1)$ & Z3 (1) \\
\hline \multirow[t]{4}{*}{ Chiroptera } & Artibeus fimbriatus & $3.2 \%(1)$ & ND & $100 \%(1)$ & TCI (1) \\
\hline & Epitesicus spp. & $6.4 \%(2)$ & ND & $50.0 \%(1)$ & TCI (1) \\
\hline & Noctilio albiventris & $3.2 \%(1)$ & ND & $0 \%$ & - \\
\hline & Total & $100 \%(31)$ & $38.7 \%(12)$ & $91.7 \%(11)$ & TCI (10)/Z3 (1) \\
\hline
\end{tabular}

* Seronegative animal where parasites could be recovered.

$\mathrm{ND}=$ not determined. 
TABLE 4

Serum prevalence of $T$. cruzi infection by immunofluorescence assay in domestic animals examinated in areas where Chagas disease outbreaks occurred in Brazil (Navegantes-Santa Catarina stateApril 2005, Redenção-Ceará state-May 2006, and Cachoeiro do Arari-Pará state-November 2006)

\begin{tabular}{lccc}
\hline Species & $\begin{array}{c}\text { Localities } \\
\text { (total of animals) }\end{array}$ & $\begin{array}{c}\text { Positive } \\
\text { animals }\end{array}$ & $\begin{array}{c}\text { Serological } \\
\text { titers range }\end{array}$ \\
\hline Dog & SC (40) & $50 \%(20)$ & $1: 40-1: 80$ \\
& CE (16) & $18.7 \%(3)$ & $1: 40-1: 80$ \\
Pig & PA (12) & $41.7 \%(5)$ & $1: 40-1: 80$ \\
\hline SC $=$ Santa Catarina State; CE $=$ Ceará state; PA = Pará state.
\end{tabular}

T. laurentius was shown to be highly exposed to infection and important in maintaining the parasite cycle in the wild, as noted by the high seroprevalence observed, even in recently weaned animals. It has already been shown that $T$. cruzi experimental infection of this species results in severe tissue damage that may predispose these rodents (especially the young) to be predated on by larger mammals (e.g., adult opossums), fostering parasite transmission. ${ }^{52}$ In Redenção, seropositive rodents displayed low parasitemias, because no positive hemoculture was achieved. In contrast, $M$. domestica and $D$. albiventris displayed higher parasitemia and, therefore, $T$. cruzi transmissibility potential, as expressed by the elevated rates of positive hemocultures and the fact that one $M$. domestica displayed tripomastigote forms in fresh blood preparation, the only animal in this study with a positive blood smear. The $T$. cruzi recovery from seronegative $M$. domestica probably occurred because of a recent infection, where specific antibodies could not yet be detected. Altogether, these data suggest two distinct roles played by the marsupials in Redenção: maintaining and transmitting the parasite when predated on (in the same way as T. laurentius) and transmitting to the triatomine vector.

Navegantes and Redenção displayed good overall conditions and an urban profile, so humans do not continuously expose themselves to the wild environment. Despite the high prevalence of infection in the small mammalian fauna, the outbreaks reported in these places can be considered accidents that may happen again, but only idiosyncratically. In contrast, Cachoeiro do Arari, an Amazonian varzean region, displayed a panzootic scenery, shown by the high prevalence of infection and positive hemocultures of almost all captured mammals and a tight human interaction with the wild environment. T. cruzi infection was spread among terrestrial, arboreal, and flying mammals, showing that parasite transmission was occurring in all ecologic strata. In this sense, all collected animal species were shown to be suitable hosts for $T$. cruzi and participate in the transmission cycle. Here, the reduction of small mammalian diversity was not so obvious, but one important sign was observed: the expressive abundance of the marsupial D. marsupialis (Table 3). Indeed, the high relative abundance of this reservoir species is an early sign of environmental disturbance caused by human action. $^{45,50}$ It is worth mentioning that, in comparison to the other studied areas, Cachoeiro do Arari presents the highest degree of preserved original biota and, consequently, the lowest degree of environmental disturbance. Hence, Cachoeiro do Arari showed the classic picture of acquisition of Chagas disease as a consequence of the entrance of hu- mans in a very wide and active wild transmission cycle of $T$. cruzi.

Besides dogs, the domestic animals in the T. cruzi transmission net in Cachoeiro do Arari also included pigs (Table 4). However, in both species, the parasitosis seems to have reached its dead-end hosts, because 1) infectivity of triatomines is not probable given that hemocultures of these animals were all negative; 2) these animals have no natural predators in the area; and 3) they seem to not be the main food sources for triatomines because of the high availability of blood sources in the wild.

Areas that present a predominance of monocultures (habitat loss), a reduction in mammalian fauna diversity, and/or domestic areas in close proximity to the wild are significant candidates to increase and spread the $T$. cruzi transmission net beyond wild habitats. In these areas, domestic animals represent the last obstacle before parasite populations reach humans. Indeed, domestic animals should be considered sentinels of a $T$. cruzi transmission net, which have to be surveyed to identify risk areas.

The panzootic situation observed in Cachoeiro do Arari showed a very well-established and broad transmission cycle of $T$. cruzi to which humans are highly exposed. The impact of açaí exploitation, common throughout the Amazonian region, represents an important threat to human health because new cases continue to appear in other localities. The absence of domiciliary triatomines has excluded the Amazonian region from the Brazilian Chagas disease map for a long time. Presently, however, special attention should be given to this region because 1) large areas continue to be deforested and replaced by Açaí monoculture; 2) human infection rates are increasing in that region; and 3) local health professionals are not qualified to face this new problem.

Altogether, the outbreaks of Chagas disease in such distinct ecologic scenarios reflect the significant biological versatility of $T$. cruzi and point to its highly complex epidemiology, which still needs to be clarified. These outbreaks also point to the importance of human action as a risk factor for the emergence of the characteristic epidemiologic picture of orally transmitted Chagas disease.

Infection through an oral route reflects the disease's ancient transmission strategy among humans. Ancient men probably acquired the infection predominantly through the oral route, through consumption of raw meat. The vectorial transmission, already important when the ancient hunter and gatherer men started to use caves as shelter, regained importance a long time thereafter, in the mud dwellings built after European colonization, when transmission was caused by domiciliated T. infestans. Presently, with the control of this triatomine species and because of forest devastation, the oral route once more assumes epidemiologic importance. This is not a new epidemiologic profile of the parasite transmission but a re-emergence of an ancient one.

Received March 12, 2008. Accepted for publication June 20, 2008.

Acknowledgments: The authors thank the Secretary of Health from Santa Catarina and Pará states and the Endemy Nucleus from Ceará state and their staff technicians for making this work possible. The authors also thank Dr. Vera Bongertz for insightful comments and English correction and the CGLab and Chagas disease National Control Program of the Brazilian Health Ministry, the Direction of the Oswaldo Cruz Institute, and the Vice-presidency of Reference Service and Environment for investing in our research. 
Financial support: This study was supported by IOC/FIOCRUZ, VPSRA/FIOCRUZ, CGLab/MS, PAPES/FIOCRUZ, CNPq, and FAPERJ.

Authors' addresses: André Luiz R. Roque, Samanta C. C. Xavier, Ana Cláudia M. Duarte, and Ana M. Jansen, Laboratory of Tripanosomatid Biology, Oswaldo Cruz Institute, FIOCRUZ, Av. Brasil 4365, Pav. Carlos Chagas, 3 andar, CEP 21040-900, Rio de Janeiro/ RJ, Brazil, Tel: 55-21-25984324, Fax: 55-21-25606572, E-mail: jansen@ioc.fiocruz.br. André Luiz R. Roque, Laboratory of Leishmaniasis Research, Oswaldo Cruz Institute, FIOCRUZ, Av. Brasil 4365, Pav. Leônidas Deane, sala 509, CEP 21040-900, Rio de Janeiro/ RJ, Brazil, Tel: 55-21-38658226, E-mail: roque@ioc.fiocruz.br. Marconny G. da Rocha and Paulo S. D'Andrea, Laboratory of Biology and Parasitology of Wild Reservoir Mammals, Oswaldo Cruz Institute, FIOCRUZ, Av. Brasil 4365, Pav. Arthur Neiva, sala 14, CEP 21040-900, Rio de Janeiro/RJ, Brazil, Tel: 55-21-25984338, Fax: 5521-22803740, E-mail: dandrea@ioc.fiocruz.br.

Reprint requests: André Luiz R. Roque, Laboratory of Tripanosomatid Biology, Oswaldo Cruz Institute, FIOCRUZ, Av. Brasil 4365, Pav. Carlos Chagas, 3 andar, CEP 21040-900, Rio de Janeiro/RJ, Brazil, E-mail: roque@ioc.fiocruz.br.

\section{REFERENCES}

1. Shofield CJ, Janin J, Salvatella R, 2006. The future of Chagas disease control. Trends Parasitol 22: 583-588.

2. Dujardin JP, Schofield CJ, Tibayrenc M, 1998. Population structure of Andean Triatoma infestans: allozyme frequencies and their epidemiological relevance. Med Vet Entomol 12: 20-29.

3. Bargues MD, Klisiowicz DR, Panzera F, Noireau F, Marcilla A, Perez R, Rojas MG, O'Connor JE, Gonzalez-Candelas F, Galvao C, Jurberg J, Carcavallo RU, Dujardin JP, Mas-Coma S, 2006. Origin and phylogeography of the Chagas disease main vector Triatoma infestans based on nuclear rDNA sequences and genome size. Infect Genet Evol 6: 46-62.

4. Pinto Dias JC, 2000. Epidemiologia. Brener Z, Andrade Z, Barral-Netto M, eds. Trypanosoma cruzi e Doença de Chagas. Rio de Janeiro, Brazil: Guanabara Koogan, 48-74.

5. Barbosa PRB, 2006. The oral transmission of Chagas disease: an acute form of infection responsible for regional outbreaks. Int J Cardiol 112: 132-133.

6. Dias JCP, 2006. Notas sobre o Trypanosoma cruzi e suas características bio-ecológicas como agente de enfermidades transmitidas por alimentos. Rev Soc Bras Med Trop 39: 370-375.

7. Buscaglia CA, Di Noia JM, 2003. Trypanosoma cruzi clonal diversity and the epidemiology of Chagas disease. Microbes Infect 5: 419-427.

8. Stevens J, Noyes H, Gibson W, 1998. The evolution of Trypanosomes infecting humans and primates. Mem Inst Oswaldo Cruz 93: 669-676.

9. Gaunt M, Miles M, 2000. The ecotopes and evolution of triatomine bugs (triatominae) and their associated trypanosomes. Mem Inst Oswaldo Cruz 95: 557-565.

10. Briones MRS, Souto RP, Stolf BS, Zingales B, 1999. The evolution of two Trypanosoma cruzi subgroups inferred from rRNA genes can be correlated with the interchange of American mammalian faunas in the Cenozoic and has implications to pathogenicity and host specificity. Mol Biochem Parasitol 104: 219-232.

11. Yeo M, Acosta N, Llewellyn M, Sanchez H, Adamson S, Miles GA, Lopez E, Gonzalez N, Patterson JS, Gaunt MW, de Arias AR, Miles MA, 2005. Origins of Chagas disease: Didelphis species are natural hosts of Trypanosoma cruzi I and armadillos hosts of Trypanosoma cruzi II, including hybrids. Int $J$ Parasitol 35: 225-233.

12. Aufderheide AC, Streitz W, Madden M, Streitz J, Buikstra J, Guhl F, Arriaza B, Renier C, Wittmers LE Jr, Fornaciari G, Allison M, 2004. A 9,000-year record of Chagas disease. Proc Natl Acad Sci USA 101: 2034-2039.

13. Lima VS, Iniguez AM, Otsuki K, Ferreira LF, Araújo A, Vicente ACP, Jansen AM, 2008. Chagas disease by Trypanosoma cruzi lineage I in huntergatherer ancient population in Brazil. Emerg Infect Dis 14: 101-102.
14. de Freitas JM, Augusto-Pinto L, Pimenta JR, Bastos-Rodrigues L, Gonçalves VF, Teixeira SMR, Chiari E, Junqueira AC, Fernandes O, Macedo AM, Machado CR, Pena SD, 2006. Ancestral genomes, sex and the population structure of Trypanosoma cruzi. PLoS Pathog 2: 226-235.

15. Pedroso A, Cupolillo E, Zingales B, 2007. Trypanosoma cruzi: Exploring the nuclear genome of zymodeme 3 stocks by chromosome size polymorphism. Exp Parasitol 116: 71-76.

16. Herrera H, Lisboa CV, Pinho AP, Olifiers N, Bianchi FL, Rocha FL, Mourão GM, Jansen AM, 2008. The coati (Nasua nasua, Carnivora, Procyonidae) as a reservoir host for the main lineages of Trypanosoma cruzi in the Pantanal region, Brazil. Trans R Soc Trop Med Hyg (in press).

17. Camandaroba EL, Pinheiro Lima CM, Andrade SG, 2002. Oral transmission of Chagas disease: importance of Trypanosoma cruzi biodeme in the intragastric experimental infection. Rev Inst Med Trop Sao Paulo 44: 97-103.

18. Steindel M, Kramer Pacheco L, Scholl D, Soares M, de Moraes MH, Eger I, Kosmann C, Sincero TC, Stoco PH, Murta SM, de Carvalho-Pinto CJ, Grisard EC, 2008. Characterization of Trypanosoma cruzi isolated from humans, vectors, and animal reservoirs following an outbreak of acute human Chagas disease in Santa Catarina State, Brazil. Diagn Microbiol Infect Dis 60: 25-32.

19. Nery-Guimarães F, da Silva NN, Clausell DT, de Mello AL, Rapone T, Snell T, Rodrigues N, 1968. Um surto epidêmico de doença de Chagas de provável transmissão digestiva, ocorrido em Teutônia (Estrela-Rio Grande do Sul). Hospital (Rio J) 73: 73-110.

20. Deane MP, Lenzi HL, Jansen AM, 1984. Trypanosoma cruzi: vertebrate and invertebrate cycles in the same mammal host, the opossum Didelphis marsupialis. Mem Inst Oswaldo Cruz 79: 513-515.

21. Umezawa ES, Shikannai-Yasuda MA, Gruber A, PereiraChiccola VL, Zingales B, 1996. Trypanosoma cruzi defined antigens in the serological evaluation of an outbreak of acute Chagas' disease in Brazil (Catolé do Rocha, Paraíba). Mem Inst Oswaldo Cruz 94: 395-398.

22. SVS-Secretaria de Vigilância em Saúde, 2005. Doença de Chagas Aguda no Município de Santana/Amapá. Brasília, Brazil: Secretaria de Vigilância em Saúde.

23. SESA-Núcleo de Epidemiologia, 2006. Doença de Chagas Aguda. Fortaleza, Brazil: Núcleo de Epidemiologia.

24. Bonvicino CR, Otazú IB, Vilela JF, 2005. Karyologic and molecular analysis of Proechimys Allen, 1899 (Rodentia, Echimyidae) from the Amazonian region. Arq Mus Nac 63: 191-200.

25. Camargo ME, 1966. Fluorescent antibody test for the serodiagnoses of American Trypanosomiasis: technical modification employing preserved culture forms of Trypanosoma cruzi in a slide test. Rev Inst Med Trop Sao Paulo 8: 227-234.

26. Herrera L, D'Andrea PS, Xavier SCC, Mangia RH, Fernandes O, Jansen AM, 2005. Trypanosoma cruzi infection in wild mammals of the National Park "Serra da Capivara", and its surroundings (Piauí, Brazil), endemic for Chagas disease. Trans $R$ Soc Trop Med Hyg 99: 379-388.

27. Vaz VC, D'Andrea PS, Jansen AM, 2007. Effects of habitat fragmentation on wild mammal infection by Trypanosoma cruzi. Parasitology 134: 1-9.

28. Brasil MS-SVS, 2003. Manual de Vigilância e Controle da Leishmaniose Visceral: Normas e Manuais Técnicos (Série A). Brazil: Ministério da Saúde, Brasília, Distrito Federal.

29. Sambrook J, Fritsch EF, Maniatis T, 1989. Molecular Cloning: A Laboratory Manual. New York: Cold Spring Harbor Laboratory Press.

30. Fernandes O, Mangia RH, Lisboa CV, Pinho AP, Morel CM, Zingales B, Campbell DA, Jansen AM, 1999. The complexity of the complexity of the sylvatic cycle of Trypanosoma cruzi in Rio de Janeiro State revealed by non-transcribed spacer of the mini exon gene. Parasitology 118: 161-166.

31. Barretto MP, Ribeiro RD, Belda Neto FM, 1978. Estudos sobre reservatórios e vectores silvestres do Trypanosoma cruzi. LXVIII: Infecção de mamíferos pela via oral. Rev Bras Biol 38: 455-459.

32. Calvo Mendez ML, Nogueda Torres B, Alejandre Aguilar R, 
1992. The oral route: an access port for Trypanosoma cruzi. Rev Latinoam Microbiol 34: 39-42.

33. Hoft DF, Farrar PL, Kratz-Owens K, Shaffer D, 1996. Gastric invasion by Trypanosoma cruzi and induction of protective mucosal immune responses. Inf Immun 64: 3800-3810.

34. Cortez M, Silva MR, Neira I, Ferreira D, Sasso GR, Luquetti AO, Rassi A, Yoshida N, 2006. Trypanosoma cruzi surface molecule gp90 down regulates invasion of gastric mucosal epithelium in orally infected mice. Microbes Infect 8: 36-44.

35. Reinhard KJ, Ambler JR, Szuter CR, 2007. Hunter-gatherer use of small animal food resources: coprolite evidence. Int $\mathrm{J} O s$ teoarchaeol 17: 416-428.

36. Ostfeld RS, Keesing F, 2000. The function of biodiversity in the ecology of vector-borne zoonotic diseases. Can J Zool 78: 2061-2078.

37. McCallum H, Dobson A, 2002. Disease, habitat fragmentation and conservation. Proc R Soc Lond B Biol Sci 269: 2041-2049.

38. Deem SL, Karesh WB, Weisman W, 2001. Putting theory into practice: wildlife health in conservation. Conserv Biol 15: 1224-1233.

39. Patz JA, Graczyk TK, Geller N, Vittor AY, 2000. Effects of environmental change on emerging parasitic diseases. Int $J$ Parasitol 30: 1395-1405.

40. Teixeira AR, Monteiro PS, Rebelo JM, Arganaraz ER, Vieira D, Lauria-Pires L, Nascimento R, Vexenat CA, Silva AR, Ault SK, Costa JM, 2001. Emerging Chagas disease: trophic network and cycle of transmission of Trypanosoma cruzi from palm trees in the Amazon. Emerg Infect Dis 1: 100-112.

41. Schmidt KA, Ostfeld RS, 2001. Biodiversity and the dilution effect in disease ecology. Ecology 82: 609-619.

42. Keesing F, Holt RD, Ostfeld RS, 2006. Effects of species diversity on disease risk. Ecol Lett 9: 485-498.

43. Chaves LF, Hernandez MJ, Dobson AP, Pascual M, 2007.
Sources and sinks: revisiting the criteria for identifying reservoirs for American cutaneous leishmaniasis. Trends Parasitol 23: 311-316.

44. Dobson A, Cattadori I, Holt RD, Ostfeld RS, Keesing F, Krichbaum K, Rohr JR, Perkins SE, Hudson PJ, 2006. Sacred cows and sympathetic squirrels: The importance of biological diversity to human health. PLoS Med 3: e231.

45. Austad SN, 1988. The adaptable opossum. Sci Am 258: 98-104.

46. Pinto CM, Ocaña-Mayorga S, Lascano MS, Grijalva MJ, 2006. Infection by trypanosomes in marsupials and rodents associated with human dwellings in Ecuador. J Parasitol 92: 12511255.

47. Ostfeld RS, Keesing F, 2000. Biodiversity and disease risk: the case of Lyme disease. Conserv Biol 14: 722-728.

48. Chaves LF, Hernandez MJ, 2004. Mathematical modeling of American cutaneous leishmaniasis: incidental hosts and threshold conditions for infection persistence. Acta Trop 92: 245-252.

49. Kilpatrick AM, Kramer LD, Jones MJ, Marra PP, Daszak P, 2006. West Nile virus epidemics in North America are driven by shifts in mosquito feeding behavior. PLoS Biol 4: e82.

50. Olifiers N, Gentile R, Fiszon JT, 2005. Relation between smallmammal species composition and anthropic variables in the Brazilian Atlantic Forest. Braz J Biol 65: 495-501.

51. Urdaneta-Morales S, Nironi I, 1996. Trypanosoma cruzi in the anal glands of urban opossums. I-Isolation and experimental infections. Mem Inst Oswaldo Cruz 91: 399-403.

52. Roque ALR, D'Andrea PS, Andrade GB, Jansen AM, 2005. Trypanosoma cruzi: distinct patterns of infection in the sibling caviomorph rodent species Thrichomys apereoides laurentius and Thrichomys pachyurus (Rodentia, Echimyidae). Exp Parasitol 111: 37-46. 